\title{
A Laboratory Setup for the Evaluation of the Effects of BACS and TBM Systems on Lighting
}

\author{
M. Beccali, M. Bonomolo, A. Galatioto, M.G. Ippolito, G. Zizzo \\ DEIM - Department of Energy, Information Engineering and Mathematical Models \\ Università di Palermo \\ Palermo, Italy \\ gaetano.zizzo@unipa.it
}

\begin{abstract}
The paper focuses on the evaluation of the impact of Building Automation Control Systems (BACS) and Technical Building Management (TBM) systems on the performance of the lighting system in a residential building. In particular, this work shows a laboratory setup, installed at the DEIM of the University of Palermo, for simulating a typical apartment. The paper describes the laboratory, the lighting system and the BAC system installed and the test facility for evaluating the electricity consumption in presence and in absence of automation. The laboratory has been built within a research project funded by the Italian Minister of University and Research in the framework of the PON Smart Cities and Communities and Social Innovation "I-Next" (PON04a2_H).
\end{abstract}

Keywords- buildings controls; energy efficiency in buildings; lighting; BAC factors.

\section{INTRODUCTION}

The European energy saving policy has just achieved great results by means of the Energy Performance in Building Directive [1] adopted by Member States. In this way, the global primary energy consumption decreased by just $0.9 \%$ in 2014 compared to 2013 ones [2] and in this framework, a key role has been played by the enhancement of building energy performances. Indeed, rigorous energy saving measures have been applied on new buildings, in order to achieve NZEB Standards $[3,4]$.

However, the most part of primary energy consumption is due to existing buildings, hence, their energy refurbishment becomes fundamental in order to achieve the European Directive "2020" [1] goals.

Today, as demonstrated by a study implemented by Harvey et al., the most part of building energy demand is due to existing building stock [5]. For this reason, the current international debate is focused, not only on best "conventional" actions in building retrofit but also on the definition and application of NZEB target on existing buildings [6] as a new worldwide challenge.

It is well known that, buildings energy performance depends not only on thermal but also on electrical factors. In particular, the European Standard EN 15232 [7] puts into evidence the importance of the presence of Building
Automation Control Systems (BACS) and Technical Building Management (TBM) systems.

It is important to underline, how the current edition of the Energy Performance in Building Directive (Directive 2010/31/EU [8]), differently from the old version (Directive 2002/91/EC [9]), gives a great role to automation, control and monitoring systems. In particular, the new EPBD encourages the use of active control systems and intelligent metering systems for energy saving purposes whenever a building is constructed or undergoes major renovation in line with Directive 2009/72/EC [10].

Moreover, Directive 2012/27/EU [1] on energy efficiency explicitly refers to automation as a way to achieve energy saving through the implementation of demand response (DR) policies, and the wide spread application of smart meters.

Indeed, a potential for energy savings lays on the use, control and interaction of heating/cooling systems, appliances and electric devices, in order to reach their full efficiency during normal operation, also thanks to the recourse to specific software systems that orchestrate all energy facilities in the house [11-13].

The standard EN 15232 provides a list of BACS and TBM functions that can affect the energy performance of buildings and introduces four different BAC efficiency classes:

- Class A: High energy performance BACS and TBM systems;

- Class B: Advanced BACS and TBM systems;

- $\quad$ Class C: Standard BACS;

- Class D: Non-energy efficient BACS.

These classes refer only to the installed BACS and TBM systems and not to the building as a whole, and they are not correlated to the energy classes defined by the European Standard EN 15217 [14].

In this paper the first part of a study is presented on the impact of BACS and TBM systems on the energy consumptions of the lighting system of a residential building. 
In particular the paper shows a laboratory setup, installed at the DEIM - Department of Energy, Information Engineering and Mathematical Models of the University of Palermo, for simulating a typical apartment.

The paper describes the laboratory, the lighting system and the BAC system installed and the on-field test campaign that will be done for evaluating the electricity consumption in presence and in absence of automation. For the classification of the BAC systems, the Italian CEI Guide 205-18 [15] is taken into account.

In a second paper will be presented the results of the calculations done for evaluating the $\mathrm{BAC}$ factor for the simulated apartment.

\section{THE LABORATORY}

\section{A. Geometrical characteristics}

In order to verify the impact and actual advantages of BAC and TBM systems, a monitoring of illuminance values and electrical consumption has been carried out. This test were conducted in the laboratory located at the DEIM of the University of Palermo.

The building is located in Palermo in the climatic zone B, according to the Decree DPR 412/93 classification [16]. The apartment area is $106 \mathrm{~m}^{2}$ and the height is $4.40 \mathrm{~m}$ including the false ceiling, and $3.40 \mathrm{~m}$ excluding false ceiling.

Lab configuration's aim is to simulate a typical apartment for a three members family, including:

- $\quad$ an entrance zone;

- a living room;

- a dining room;

- a kitchen;

- a bedroom;

- a bathroom.

The apartment has four windows, equipped by doubleglazing with aluminum frames (without thermal break). The windows are located on the South-East side overlooking a green roof (albedo average value $=0.25$ ) and are $2.40 \mathrm{~m}$ wide and $2.90 \mathrm{~m}$ high. Medium height plants on the green roof cover two windows. Furthermore, the facade is partially shaded by a solar shelter (Fig. 1), whose area is $2.70 \times 19 \mathrm{~m}$, where a hybrid solar photovoltaic/thermal (PV/th) system is installed. This solar system is connected with both a HVAC system (a solar thermally driven advanced DEC system) and the electric grid though a storage/management system.

\section{B. The lighting system}

Generally, apartments have various zones where different tasks are performed. Every task requires a specific optimal illuminance value. At the moment, a Standard suggesting illuminance values and sources and luminaires characteristics for residential spaces does not exist. So, for setting up the laboratory and select the luminaries, the authors have referred to the indications of the old Italian Standard UNI 10380 [17] and, according to it, new luminaires have been chosen to provide correct illuminance levels on the working surfaces together with appropriate quality requirements.

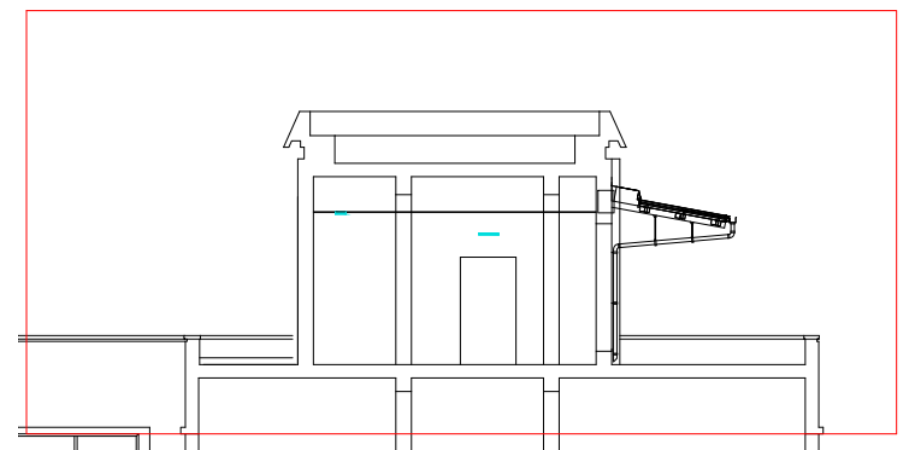

Fig. 1. The solar shelter.

Table I shows the design illuminance values for every zone and every activity, the colors graduation, the glare classification and the color rendering index (CRI) of lamps, suggested by the Standard for a common apartment.

Starting from the values in Table $\mathrm{I}$, in order to size luminaires and choose lamps typologies, a lighting simulation have been carried out.

TABLE I. ILLUMinANCE VALUES, COLOR GRADUATION AND GLARE ClASSIFICATION SUGGESTED BY UNI STANDARD 10380

\begin{tabular}{|c|c|c|c|}
\hline $\begin{array}{c}\text { Space, typology, } \\
\text { visual task, task to } \\
\text { perform }\end{array}$ & E (lux) & $\begin{array}{c}\text { Color } \\
\text { gradation }\end{array}$ & $\begin{array}{c}\text { Glare } \\
\text { classification }\end{array}$ \\
\hline Passageway & $50-100-150$ & $\mathrm{~W}$ & $\mathrm{~A}$ \\
\hline Reading zone & $200-300-500$ & $\mathrm{~W}$ & $\mathrm{~A}$ \\
\hline Writing zone & $300-500-750$ & $\mathrm{~W}$ & $\mathrm{~A}$ \\
\hline Dining room & $100-150-200$ & $\mathrm{~W}$ & $\mathrm{~A}$ \\
\hline Kitchen & $200-300-500$ & $\mathrm{~W}$ & $\mathrm{~A}$ \\
\hline $\begin{array}{c}\text { Bathroom: } \\
\text { General lighting } \\
\text { Mirror (vertical } \\
\text { surface) }\end{array}$ & $50-100-150$ & $\mathrm{~W}$ & $\mathrm{~B}$ \\
\hline $\begin{array}{c}\text { Bedroom: } \\
\text { General lighting } \\
\text { Closet (vertical } \\
\text { surface) }\end{array}$ & $200-300-500$ & & $\mathrm{~B}$ \\
Bedroom & $200-300-500$ & $\mathrm{~W}$ & $\mathrm{~B}$ \\
\hline
\end{tabular}

Originally, the laboratory was equipped with only four pendant luminaires with $36 \mathrm{~W}$ fluorescent lamps and total installed power of $576 \mathrm{~W}$

In the new configuration, in all the areas the indoor pendant luminaires have been substituted with LED pendant luminaires (Arano LED BPS 640 W21L125 1XLED/480 LIN$\mathrm{PC}$ ) having a rated power equal to $54 \mathrm{~W}$ and in the kitchen and in the entrance zone, four $15 \mathrm{~W}$ mono optic indoor spotlight have been installed (two in the entrance zone and two in the kitchen). The total installed power is $276 \mathrm{~W}$. 


\section{The BAC system}

In the laboratory the following systems are present:

- $\quad$ electric energy distribution system;

- $\quad$ lighting system;

- heating/cooling system.

The lighting system is managed by a BAC system programmable by a software and is composed by:

- $\quad$ n.2 light and motion detectors;

- $\quad$ n.1 scenario programmer;

- $\quad$ n.1 touch dimmer;

- $\quad$ n. 3 manual actuators;

- $\quad$ n. 4 basic controls (common switches).
In the living room and in the dining room ceiling, two light and motion detectors are installed. Their location has been optimised through a daylight simulation of the ambients (Fig. 2 ). The touch dimmers control three of the four pendant luminaires, located in the dining and in the living room. Thanks to the motion detectors the luminaries installed in the two rooms are switched on only if someone enter the room and only if the illuminance due to natural lighting is below a fixed threshold.

In this way the function F48A (presence detection, light regulation and automatic ON/OFF) defined by CEI Guide 205-18 for lighting control is implemented in the two rooms.

The lights in the other rooms are managed in order to assure they are switched off at a fixed time, in the case that the inhabitants of the rooms let the lights on.

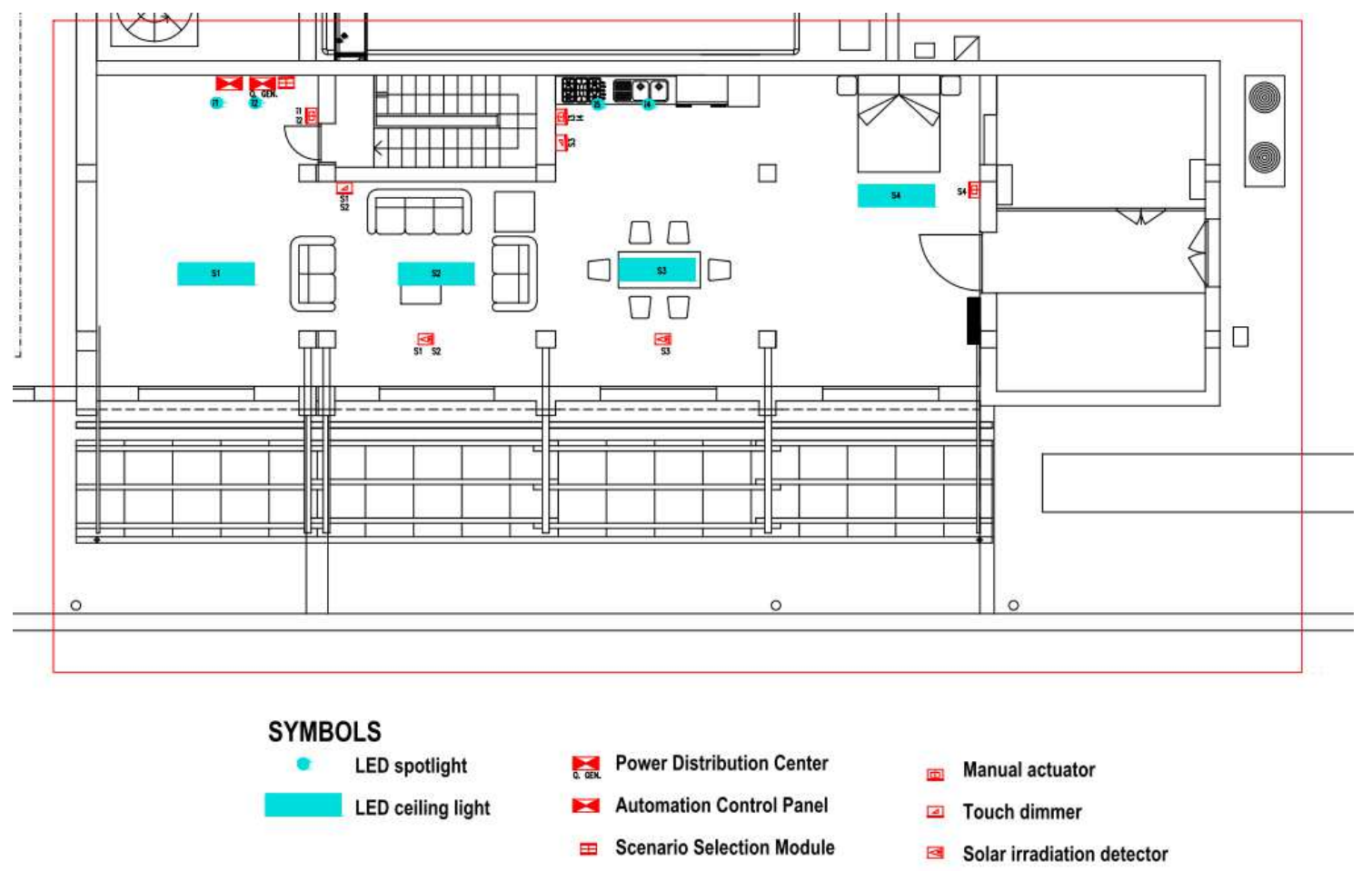

Fig. 2. Laboratory floor plan.

In this way the function F49A (presence detection and automatic ON/OFF) defined by CEI Guide 205-18 for lighting control is implemented (Fig. 3).

BUs line

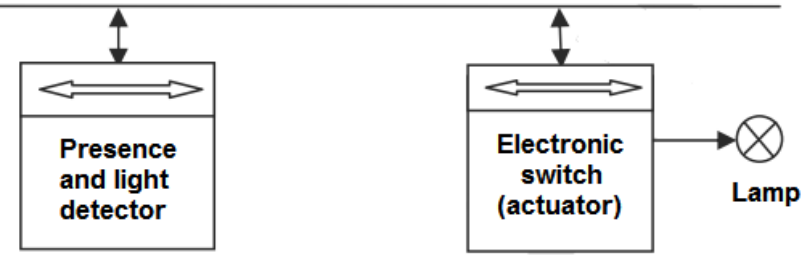

Fig. 3. Functional scheme of F48A and F49A function (CEI Guide 20518)
The BAC system manages the lighting system and it is programmable by the Software MyHome Suite by Bticino [18].

The software, in addition to the control of the lighting system, is able to configure all the devices for the automation, the energy management and temperature control and to integrate the management of some devices that require programming (for example touch screens, web servers, scenario programmers, advanced video handsets). It is designed to be used by common people and has a very userfriendly interface.

The main function of MyHome Suite are: 
Light control (switch on and switch off of lamps, luminous flux regulation of a lamp, a group of lamp or all the lamps of the apartment);

- control of electric motors or electro-pumps for water;

- $\quad$ scenario module control (recalling and/or changing scenario saved in the scenario module);

- $\quad$ sound system control (switch on and switch off of sound system, volume adjustment, switching and managing of amplifier sources, etc.);

video door entry system (opening of a door lock, control of internal video entry system panel, switch on and switch off/of the lamps in staircase, etc.).

Figure 4 shows the screenshot of the main page of the software.

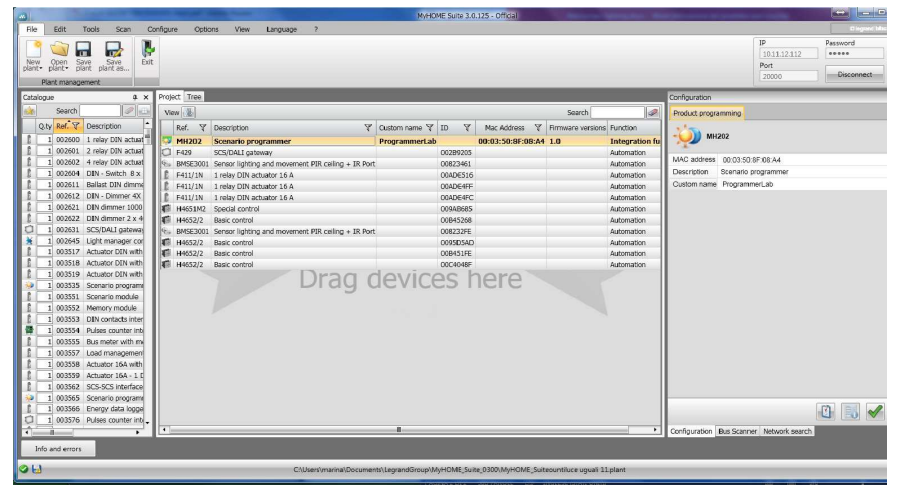

Fig. 4. Screenshot of the main windows of MyHome.

\section{THE MEASUREMENT CAMPAIGN}

In order to evaluate the reduction of the energy consumption due to the installation of the devices for the lighting automation and control described in the previous section, a measurement campaign of the illuminance and of the energy consumption has been started.

For measuring the energy consumption a common energy meter is installed in the power distribution center of the laboratory downward the circuit breaker protecting the lighting circuit. 5):

The measurement of illuminance is conducted using (Fig.

n. 1 mobile luxmeter (Delta Ohm HD 2102.2) to monitor the illuminance indoor values;

- $\quad$ n. 1 Lsi Lastem Babuc/A equipped by illuminance probe to monitor the illuminance outdoor values;

- n. 1 dataTaker DT80 Range to monitor energy consumption for lighting.

The mobile luxmeter is located in the living room at the height of a generic "coffee table" and not at the height of a work plane $(0.85 \mathrm{~m}$ in accordance with UNI 10380/1994 and UNI EN 12464-1/2011 [19]).
In order to evaluate the daylight contribution, the Daylight Factor (DF) is measured empirically. The illuminance values, indoor and outdoor, are taken with a regular step of 5 minutes during two periods of 10 days.

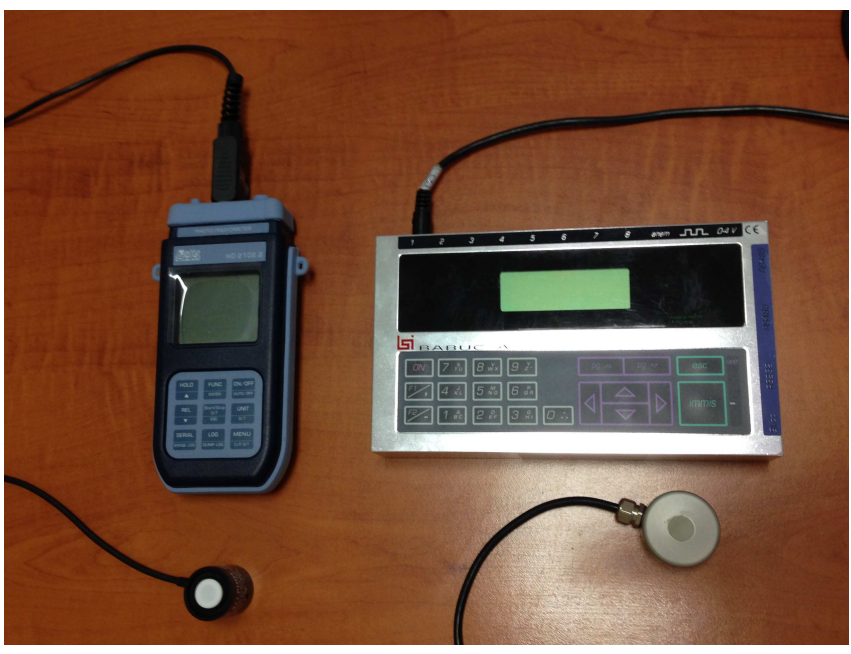

Fig. 5. Instrumentation for illuminance measures

During the two periods different lighting scenarios are set (Fig. 6):

- Bedroom lighting scenario: from 7:00 to 7:30 and from 22:00 to 00:00;

Kitchen lighting scenario: from 12:00 to 12:30 and from 20.00 to 21.30;

- $\quad$ Entrance lighting scenario: from 17:50 to 18:05 and from 18:10 to $18: 25$.

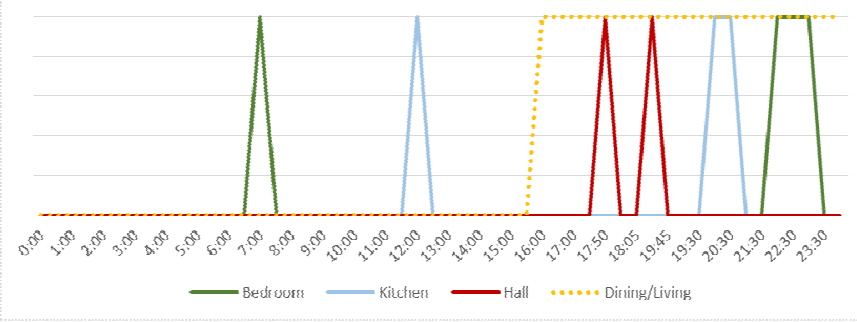

Fig. 6. Programmed scenarios.

The scenarios are generated using SirSym, a simulation tool based on a statistical approach and developed by the DEIM within the National Research Project SIRRCE [20].

In Fig 7 the screenshot of the scenario programmer webpage is shown.

For evaluating the energy savings due to the BAC system, and calculating a value of a BAC factor for the simulated apartment, the illuminance and the electricity consumption are measured in presence and in absence of automation, that is activating and then deactivating the F48A and F49A functions. 


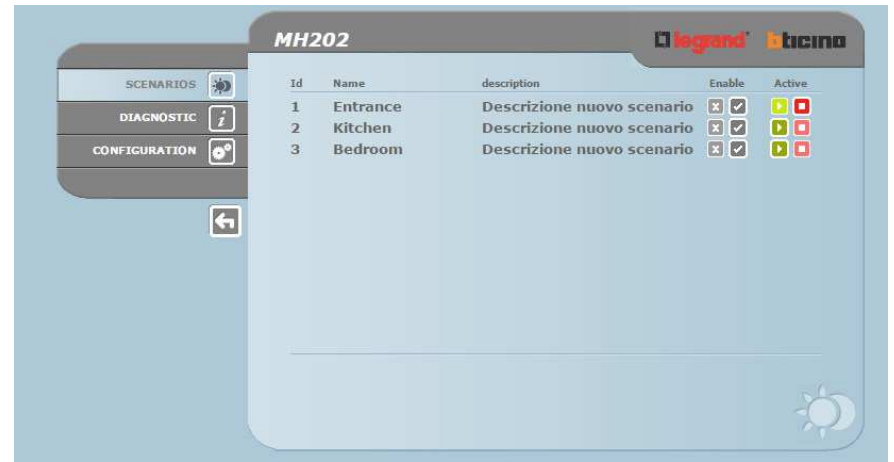

Fig. 7. Main screenshot of webpage of scenarios programmer.

The first part of the measurement campaign was started on the 31 st of July 2015 and concluded on the 9th of August. rainy.

During some of these ten days the weather was cloudy and

In Figures 8 and 9 the comparisons between the indoor and outdoor illuminance values of 3 days of this period are reported.

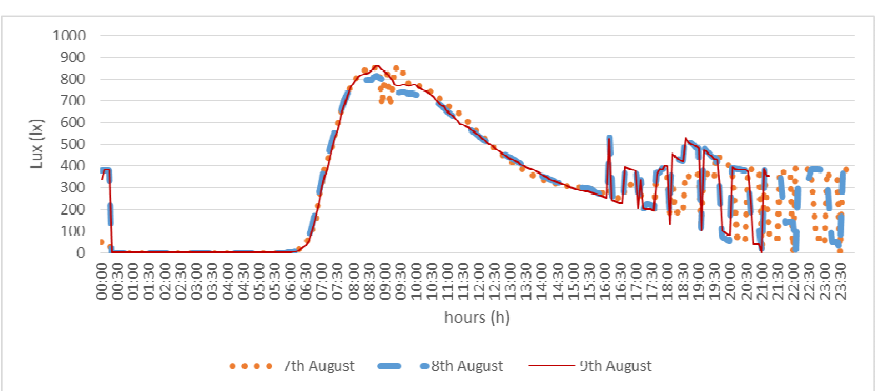

Fig. 8. Comparison of indoor illuminance values measured during three summer days.

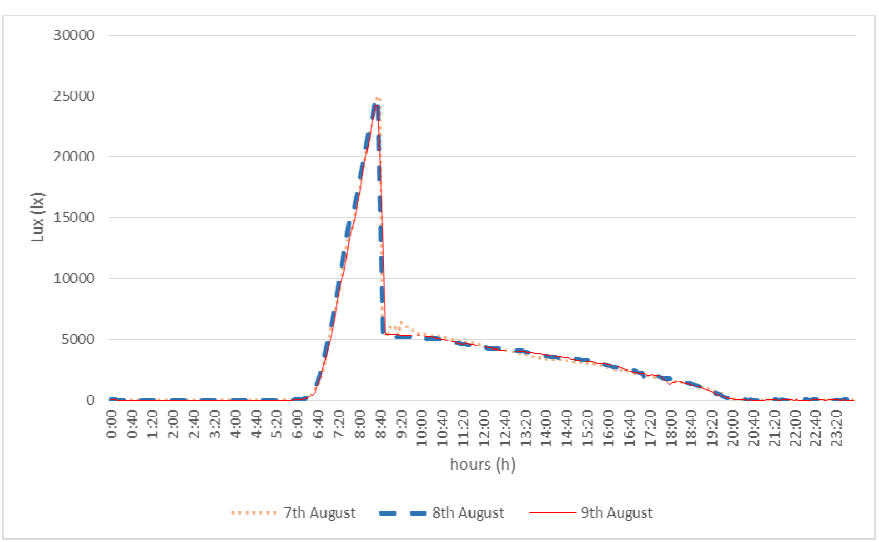

Fig. 9. Comparison of outdoor illuminance values measured during three summer days.

The peak of illuminance measured indoor was 972,6 lux (only daylight contribution) and it happens the $3^{\text {rd }}$ of August at 10:07.

It was detected that every day during the observation period at about 8:30 a.m. outdoor illuminance exceeds 25000 lux. However it is not important for the purposes of this paper because at that time the lamps were off. After 16:00 the lamps are switched on only if lux measured by the light detector were lower than 150 lux and if there is presence of people.

Figure 10 shows electrical consumption during the first measurement period. It should be noted that the $8^{\text {th }}$ of August, electric energy consumption for internal lighting is higher than the consumption measured during the other days.

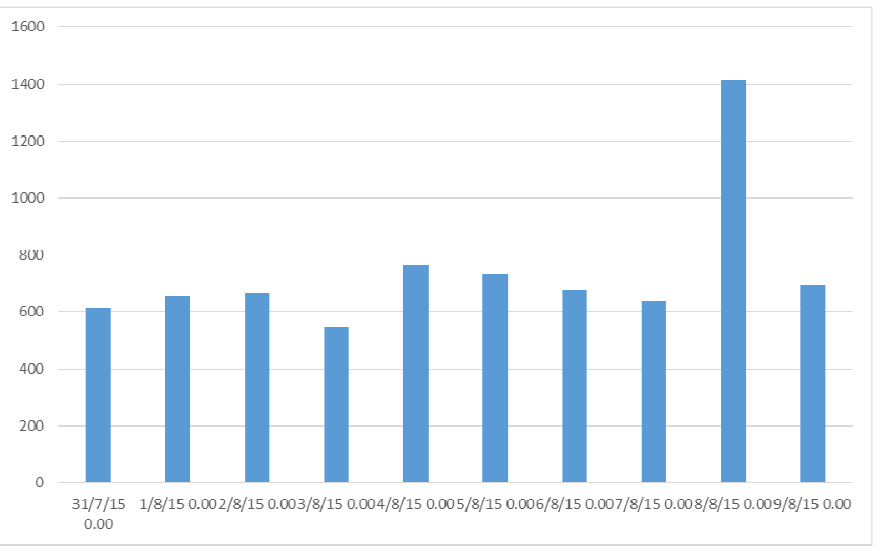

Fig. 10. Daily electric energy consumption of lighting.

\section{CONCLUSION}

The paper is the first part of a work devoted to the evaluation of the contribution given by the automation to the energy saving of an apartment.

The paper has presented a laboratory setup, installed at the DEIM of the University of Palermo, for simulating a typical apartment. The laboratory, the lighting system and the BAC system installed in the laboratory are described and the measurement campaign for evaluating the electricity consumption in presence and in absence of automation has been explained. Finally, some partial results have been presented.

In a future work the whole results of the measurement campaign will be presented together with the conclusion of the research.

\section{ACKNOWLEDGMENT}

The project has been funded by Italian Minister of University and Research in the framework of the PON Smart Cities and Communities and Social Innovation "INext" (PONO4a2_H).

Part of the data used in the paper have been obtained using the tool "SirSym" developed within the National Research Project SIRRCE funded by by the Italian Minister for the Economic Development with Decree of the 16th of February 2010.

\section{REFERENCES}

[1] Directive 2012/27/EU of The European Parliament and of the Council of 25 October 2012 on energy efficiency, amending Directives 2009/125/EC and 2010/30/EU and repealing Directives 2004/8/EC and 2006/32/EC, Official Journal of the European Union. L 315/1, 14.11.2012. 
[2] BP Statistical Review of World Energy, June 2013. Available at: www.bp.com/statisticalreview. Last access: 09 september, 2015.

[3] P. Torcellini, S. Pless, M. Deru and D. Crawley: Zero Energy Buildings. A Critical Look at the Definition, proceeding of Conference Paper NREL/CP-550-39833, June 2006.

[4] I. Sartori, A. Napolitano, K. Vossc: Net zero energy buildings: A consistent definition framework, Energy Buildings 2012;48:220-232.

[5] L.D. D. Harvey, K. Korytarova, O. Lucon, V. Roshchanka. Construction of a global disaggregated dataset of building energy use and floor area in 2010. Energy and Buildings 2014;76:488-496.

[6] M. Beccali, A. Galatioto, G. Leone, S. Longo. Is the NZEB benchmarking approach suitable for assessing energy retrofit design? Applied Mechanics and Materials Vols. 361-363 (2013) pp 402-407.

[7] European Technical Standard EN 15232, "Energy Performance of Buildings - Impact of Building Automation, Control, and Building Management”, second ed., CEN, Brussels, 2012.

[8] Directive 2010/31/EU of the European Parliament and of the Council of 19 May 2010 on the energy performance of buildings.

[9] Directive 2002/91/EC of the European Parliament and of the Council of 16 December 2002 on the energy performance of buildings.

[10] Directive 2009/72/EC of the European Parliament and of the Council of 13 July 2009 concerning common rules for the internal market in electricity.

[11] M.G. Ippolito, E. Riva Sanseverino, and G. Zizzo, "Impact of building automation control systems and technical building management systems on the energy performance class of residential buildings: An Italian case study", Energy and Buildings, Vol. 69 (2014), p. 33-40.
[12] M. J. Kofler, C. Reinisch, W. Kastner, "A semantic representation of energy-related information in future smart homes", Energy and Buildings 437 (2012) 169-179.

[13] G. Graditi, M.G. Ippolito, R. Lamedica, A. Piccolo, A. Ruvio, E. Santini, P. Siano, G. Zizzo G. Innovative control logics for a rational utilization of electric loads and air-conditioning systems in a residential building Energy and Buildings, Vol. 102 (2015), p. 1-17, ISSN: 03787788, doi:10.1016/j.enbuild.2015.05.027

[14] European Technical Standard EN 15217, Energy performance of Buildings - Methods for expressing energy performance and for the energy certification of buildings, first ed., CEN, Brussels, 2007.

[15] Italian Guide CEI 205-18, Guide to Building Automation - Identification of functional block diagrams and estimation of related energy savings, CEI, January 2011.

[16] D.P.R. n. 412, "Regolamento recante norme per la progettazione, l'installazione, l'esercizio e la manutenzione degli impianti termici degli edifici ai fini del contenimento dei consumi di energia, in attuazione dell'art. 4, comma 4, della L. 9 gennaio 1991, n. 10" (in Italian), August 1993

[17] Italian Standard UNI 10380, Interior lighting with artificial light, UNI, 1994.

[18] http://www.bticino.com/myhome_suite/index.html

[19] Standard UNI EN 12464-1, Lighting of workplaces, UNI, 2011.

[20] SIRRCE: System for the residential energy optimization with summer air conditioning integration, Research Project, financed by the Italian Minister for the Economic Development with Decree of the 16th of February 2010. 